\title{
Consultation liaison psychiatry in Sri Lanka: a case for sub-specialisation
}

\author{
Raveen Hanwella
}

\section{Summary}

Liaison psychiatry has not been established in Sri Lanka as a sub-speciality. However many psychiatrists who work in general hospital settings are required to do liaison work. Patterns of referrals to a university psychiatry liaison unit were studied in order to identify the requirements in training for liaison psychiatry in Sri Lanka. A retrospective analysis of records of all new patients registered during a six month period from $1^{\text {st }}$ January 2010 in the liaison unit of the University Psychiatry Unit, Colombo was carried out. A total of 1079 patients were referred to the liaison unit during this period. The commonest reason for referral was assessment of patients who were admitted to medical or surgical wards after deliberate self harm. The variety of clinical conditions referred to liaison units highlight that psychiatry trainees need a broad knowledge of general medicine and a wide repertoire of clinical and other skills to effectively manage their patients. Specialised liaison units should be started in the general hospitals and should form the nucleus for training and establishing the field of consultationliaison psychiatry as a subspecialty in Sri Lanka.

SL J Psychiatry 2010; 1 (2):39-41

\section{Introduction}

Liaison psychiatry also known as consultation-liaison psychiatry and psychosomatic medicine in the United States is the speciality of psychiatry that deals with the interface between medicine and psychiatry. The setting is usually in a general hospital. It has two components, the consultation where the psychiatrist is asked to give an opinion regarding management of patients referred by the medical, surgical or other teams and the liaison component where the psychiatrist liaises between the patient and the referring team and carries out joint management (1).

Liaison psychiatry has not been established in Sri Lanka as a sub-speciality. However as many psychiatrists are required to do liaison work we studied the patterns of referrals to the University Psychiatry Liaison Unit, Colombo to identify the requirements in training for liaison psychiatry in Sri Lanka.

\section{History}

The French philosopher Rene Descartes (1637) in his 'Passions of the Soul' and 'The Description of the Human Body' proposed that the body had material properties and followed the law of physics whereas the mind was non-material and did not follow the laws of physics. He has been accused of creating a barrier to an integrated view of psychosomatic medicine by splitting the mind and the body. In 1818 Johann Heinroth originated the term 'Psychosomatic Medicine'. It was Edward Billings an American psychiatrist who first coined the term 'Liaison Psychiatry' and created the first formal division of consultation psychiatry in 1934 at the University of Colorado Hospital (2). George Engel another American psychiatrist who played an important role in the development of liaison psychiatry postulated the term 'Biopsychosocial Model' (1977) which overcame the divisions created by the dualism model of Descartes. The Royal College of Psychiatrists established the Faculty of Liaison Psychiatry in 1997 and the American Psychiatric Association recognised consultation liaison psychiatry as a sub-speciality in 2004 but decided to use the term psychosomatic medicine (3).

In a meta-review Ruddy and House identified six key areas of liaison psychiatry (4). They were:

1. psychological effects of physical illness or its treatment;

2. somatoform disorders;

3. self-harming behaviours;

4. emergency presentations of acute psychiatric illness to general hospitals;

5. physical effects of psychological or psychiatric treatment;

6. physical findings or behaviour raising concerns about possible physical or sexual abuse.

To this may be added a seventh especially in the Sri Lankan context, alcohol and other substance use.

The majority of psychiatry units in Sri Lanka are in General Hospitals. Therefore it is likely that psychiatrists would be called upon to provide a significant amount of consultation liaison psychiatry.

\section{Methods}

A retrospective analysis of records of the Liaison Unit of the University Psychiatry Unit, Colombo was carried out. All records of new patients registered between $1^{\text {st }}$ January 2010 and $30^{\text {th }}$ June 2010 were included in the study. National Hospital of Sri Lanka has about 3000 beds and provides specialised care in all sub-specialties except paediatrics, obstetrics and ophthalmology. 
Patients are referred to the liaison unit from other units of the National Hospital of Sri Lanka, the Eye Hospital, Castle Street Hospital for Women (CSHW) and the De Zoysa Hospital for Women (DSHW). The CSHW and DSHW are specialised Obstetric and Gynaecology hospitals. Only those referred from in-patient units were included in the analysis. The referrals to the outpatient clinics of the psychiatry unit have not been included in the analysis.

\section{Results}

A total of 1079 patients were referred to the liaison unit during a six month period. The commonest reason for referral $(35.3 \%)$ was for assessment of patients admitted to medical or surgical wards after deliberate self harm. Only about $10 \%$ of referred patients had a previous diagnosis of a psychiatric illness.

Ninety eight patients $(9.1 \%)$ presented with delirium. These are the most challenging patients for the psychiatrist. These patients were referred for opinion of the psychiatrists regarding possible psychiatric aetiology for disturbed behaviour. Many of these patients were undergoing concurrent investigations to identify a possible organic origin. Some patients were disorientated but investigation findings were normal. In assessing such patients the psychiatrist needs to have a comprehensive knowledge of general medicine and be able to liaise with general physicians and neurologists to arrive at a diagnosis.

Depression in the physically ill was diagnosed in $9.7 \%$ of patients. Several studies in Sri Lanka and other countries have indicated that in conditions such as renal failure, neurological and cardiovascular illness the rate of depression may be close to $20 \%$ [5,6]. In treating such patients, psychiatrists need to be aware of difficulties in diagnosing depression in the physically ill and possible drug interactions when prescribing treatment.

Unlike in western countries dissociative disorders are common among patients presenting to neurology units. Here too diagnosis could be challenging requiring psychiatrists to have a comprehensive understanding of neurological conditions.

Of importance is the wide variety of presentations to the liaison unit. Psychiatrists working in other psychiatry units in Sri Lanka too will encounter a similar range of clinical problems. To deal with these clinical problems the psychiatrists needs to be equipped with a range of skills.

The total number of patients referred during a six month period to one unit is an indicator of the work load of a liaison unit in a general hospital. We did not take into account the number of patients refereed to other visiting consultant psychiatrists who provide outpatient care in the hospital. The patients assessed in the liaison unit are only referrals from in-patient units. Patients referred to the out-patient clinic have not been included in the analysis.
Table 1- Diagnoses of patients attending liaison unit

\begin{tabular}{|lc|}
\hline Diagnosis & $\begin{array}{l}\text { Frequency (\%) } \\
n=1079\end{array}$ \\
\hline Deliberate self harm & $381(35.3)$ \\
Previous diagnosis of psychiatric & $115(10.7)$ \\
illness & \\
New diagnosis-psychotic disor- & $81(7.5)$ \\
ders & $98(9.1)$ \\
Delirium & $76(7.04)$ \\
Alcohol and other substance use & $15(1.3)$ \\
Dementia & $105(9.7)$ \\
Depression in physically ill & $21(1.9)$ \\
Somatoform disorder & $33(3.0)$ \\
Dissociative disorder & $57(5.3)$ \\
Grief/adjustment disorder & $16(1.5)$ \\
Post partum psychosis & $41(3.8)$ \\
No psychiatric illness & $17(1.6)$ \\
Anxiety disorders & $23(2.1)$ \\
Undiagnosed &
\end{tabular}

Some of these patients were very ill and required visits by the psychiatry team to medical and surgical units. Many patients required more than one assessment where investigation findings needed to be reviewed or collateral histories obtained. Managing these patients also require liaising with doctors and nurses from other units. Thus in addition to managing patients with psychiatric illness, liaison work takes up a considerable amount of time and resources of psychiatry units.

\section{Discussion}

The variety of clinical conditions referred to liaison units highlight that psychiatry trainees need to have broad knowledge of general medicine and a wide repertoire of clinical and other skills to effectively manage their patients.

In 2007 the European Association of ConsultationLiaison Psychiatry and Psychosomatics (EACLPP) published their guidelines for training in ConsultationLiaison Psychiatry. In the guidelines it is recommended that trainees should be trained in the following clinical disorders or situations (7).

1. Delirium/dementia and other psychiatric disorders with organic cause

2. Somatization

3. Depression and anxiety in medically ill patients

4. Suicide/self-harm (with special emphasis on the management in a medical unit and transference/ counter transference issues)

5. Addiction problems in medical settings

6. Abnormal illness behaviour in somatically ill patients 
7. Coping with chronic disease and terminal illness;

8. Chronic pain

9. Gender-specific disorders, sexual dysfunction in medically ill patients, and sexual abuse in specific patient populations (e.g. somatoform disorder and chronic pain)

10. Psychiatric co-morbidity and psychological problems in child and adolescent disorders

11. Management of patients with psychiatric disorders (e.g., psychotic and bipolar) in need of medical/ surgical treatment

In addition the European guidelines also recommend that trainees should have good communication skills with ability to use language easily understood by medical teams and be able to coordinate care with such teams.

It would also be important that the supervising consultant possesses the required knowledge and skills at a higher level. Whether it is possible for a 'part time' liaison psychiatrist, in the midst of his other general psychiatry duties carry out training in liaison psychiatry is questionable.

As regards to the organisation of a liaison psychiatry training appointment, the European guidelines recommend that the following requirements be met (5).

1. A minimum of six months full time training

2. The training should be in the second year when trainees have acquired basic knowledge and skills in general psychiatry

3. A trainee should see a minimum of 100 referrals during this period

4. Training should be based in a general hospital unit;

5. Supervision of trainees should be organised with a clearly designated supervisor and designated supervision sessions

6. A single trainer should not be responsible for an excessive number of trainees

7. Trainees should have basic expertise in general medicine prior to starting on the liaison appointment or gain such expertise during the appointment. The emphasis should be on areas of general medicine particularly related to psychiatry

For a start it would not be too difficult to initiate a six month training rotation within adult psychiatry training in Sri Lanka. In the absence of specialists in liaison psychiatry the trainees could be supervised by a general adult psychiatrist with an interest in the field.

In the future specialised liaison units could be started in the larger general hospitals and these could form the nucleus for training and establishing the field of consultation-liaison psychiatry as a subspecialty in Sri Lanka.

\section{Declaration of interest}

None

Raveen Hanwella, MBBS, MD (Psych), MRCPsych, Senior Lecturer, Department of Psychological Medicine, Faculty of Medicine, Kynsey Road, Colombo 08, Sri Lanka Email:raveenhanwella@yahoo.co.uk

\section{References}

1. http://en.wikipedia.org/wiki/Liaison_psychiatry. 2010 2010 [cited 2010; Available from: http://en.wikipedia. org/wiki/Liaison_psychiatry.

2. Blumenfield, M. and J.J. Strain, Psychosomatic medicine. 2006, Philadelphia, Pa. ; London: Lippincott Williams \& Wilkins. xxvii, 949 p.

3. Guthrie, E. and G.G. Lloyd, Handbook of liaison psychiatry. 2007, Cambridge: Cambridge University Press. xiv, 929 p.

4. Ruddy, R. and A. House, Meta-review of high-quality systematic reviews of interventions in key areas of liaison psychiatry. Br J Psychiatry, 2005; 187: 109-20.

5. Egede, L.E., Major depression in individuals with chronic medical disorders: prevalence, correlates and association with health resource utilization, lost productivity and functional disability. Gen Hosp Psychiatry, 2007; 29(5):409-16.

6. Sumanatissa M, de Silva V, Hanwella R. Prevalence of major depressive episode among patients with pre-dialysis chronic renal disease Intl.J.Psychiatry in Medicine, 2011; 41(1): 47-56

7. Sollner, W. and F. Creed, European guidelines for training in consultation-liaison psychiatry and psychosomatics: report of the EACLPP Workgroup on Training in Consultation-Liaison Psychiatry and Psychosomatics. J Psychosom Res, 2007; 62(4): 501-9. 